\title{
Having a family doctor was associated with lower utilization of hospital-based health services
}

\author{
Colman SC Fung ${ }^{1 *}$, Carlos KH Wong ${ }^{1}$, Daniel YT Fong ${ }^{2}$, Albert Lee ${ }^{3}$ and Cindy LK Lam
}

\begin{abstract}
Background: Primary care in the United States and most countries in Asia are provided by a variety of doctors. However, effectiveness of such diversified primary care in gate-keeping secondary medical services is unknown. This study aimed to evaluate health services utilization rates of hospital emergency and admission services among people who used different primary care doctors in Hong Kong.

Method: This study was a population-based cross-sectional telephone survey using structured questionnaire on health services utilization rates and pattern in Hong Kong in 2007 to 2008. Information on the choice of primary care doctors, utilization rates and patterns of primary care service were collected. Poisson and logistic regression analyses were used to explore any differences in service utilization rates and patterns among people using different types of primary care doctors.
\end{abstract}

Results: Out of 3148 subjects who completed the survey, 1896 (60.2\%) had regular primary care doctors, of whom $1150(60.7 \%)$ regarded their regular doctors as their family doctors (RFD). 1157 (36.8\%) of them did not use any regular doctors (NRD). Only $4.3 \%$ of the RFD group (vs $7.8 \%$ of other regular doctors (ORD) and $9.6 \%$ of NRD) visited emergency service and only $1.7 \%$ (vs $3.6 \%$ of ORD and $4.0 \%$ of NRD) were admitted to hospital for their last episode of illness. Regression analyses controlling for sociodemographics and health status confirmed that respondents having RFD were less likely to use emergency service than people who had NRD (OR 0.479) or ORD (OR 0.624) or being admitted to hospital (OR 0.458 vs NRD and 0.514 vs ORD) for their last episode of illness.

Conclusion: Primary care is the most effective in gate-keeping secondary care among people with regular family doctors. People without any regular primary care doctor were more likely to use emergency service as primary care. The findings supported a family doctor-led primary care model.

Trial registration number: ClinicalTrials.gov ID: NCT01422031.

Keywords: Family doctor, Health utilization, Hospitalization, Emergency services, Chinese, Count data

\section{Background}

Primary care has a great impact on the population's health and its effectiveness and accessibility are the key to health for all $[1,2]$. Primary care should be able to gate-keep hospital health services, [3-10] including accident and emergency service [11]. Experience from western countries where primary care is provided mainly by family doctors or general practitioners with standardized postgraduate training is encouraging [5,8,12-15]. Starfield et al. found that countries with a more uniform type of primary care

\footnotetext{
* Correspondence: cfsc@hku.hk

${ }^{1}$ Department of Family Medicine and Primary Care, the University of Hong Kong, 3/F., 161 Main Street, Ap Lei Chau Clinic, Ap Lei Chau, Hong Kong Full list of author information is available at the end of the article
}

providers had better health outcomes [5,8]. Primary care provided by family doctors has been found to be the most cost-effective health care service [8-10,12,16,17]. A higher supply of general practitioners and family physicians, but not other primary care doctors, was associated with lower mortality rates $[13,14]$ and higher early cancer detection rates $[15,18]$. The family-doctor model has been proposed to be the solution for the rising demand for quality primary care services for aging populations in Hong Kong [19] and the United States [20] .

Like the United States, primary care in many countries in Asia is provided by a variety of Western and Chinese medicine practitioners. Instead of seeing a primary care

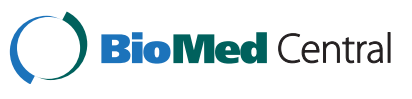

(c) 2015 Fung et al.; licensee BioMed Central. This is an Open Access article distributed under the terms of the Creative Commons Attribution License (http://creativecommons.org/licenses/by/4.0), which permits unrestricted use, distribution, and reproduction in any medium, provided the original work is properly credited. The Creative Commons Public Domain Dedication waiver (http://creativecommons.org/publicdomain/zero/1.0/) applies to the data made available in this article, unless otherwise stated. 
doctor in the community, some people in Hong Kong use emergency service of the hospital as the main provider of primary care for various reasons [21]. However, research found that $57.0 \%$ of patients attending emergency service could actually be managed by family doctors [21]. Other studies also found that the population in Hong Kong were twice as likely to consult a doctor when they were ill, compared to patients in the US and UK $[22,23]$. Consultations with more than one doctor for the same episode of illness (doctor-shopping) was another prevalent phenomenon [24]. So far, no known research has been done to investigate the effectiveness in safeguarding the utilization rates of other health care service by this kind of pluralistic primary care service, and how having a family doctor makes any difference.

This study aimed to evaluate health services utilization rates in particular those of hospital emergency and secondary specialist services among people who used different primary care doctors in Hong Kong.

\section{Method}

Analysis was done on data collected in a cross-sectional general population health service utilization survey that was carried out in two phases in summer (September to October 2007) and winter (March to April 2008). Telephone-owning households in Hong Kong were contacted by random digital dialling by the Social Sciences Research Centre of the University of Hong Kong using the computer-assisted telephone interviewing system with a $95 \%$ household coverage rate. Respondent in a selected household was randomly identified by the use of the last birthday rule. The main carer of a minor under age of 18 answered the survey as the proxy. The exclusion criteria were non-residential numbers; Inability to communicate in Cantonese, Putonghua or English; Refusal to telephone interview; and no contact after 5 attempts. Details of the study design are described in previous papers [25-27].

A structured questionnaire concerning the presence and type of regular primary care doctors, prevalence (likelihood) of utilization of different health services for their last illness episode, medical health services utilization rates in the past four weeks, health status and socio-demographics was administered. No time limit was set when asking the respondents' last illness episode (likelihood), and four weeks was used as the consistent time reference for the recall of all types of health service utilization, including emergency services, hospital admissions, and primary care doctor or family doctor consultations for the monthly health services utilization rates. A total of 5174 eligible households were contacted and 3148 (60.8\%) subjects, with 1616 and 1532 in the summer and winter phases respectively, completed the crosssectional survey.
Subjects were classified into three groups: the first one "Regular Family Doctor group" (RFD) included subjects who reported to have a regular primary care doctor and considered him/her as the family doctor; the second group was "Other Regular Doctor group" (ORD), involving subjects who had a regular primary care doctor whom was not considered as his/her family doctor; the third one was "No Regular Doctor group" (NRD) for subjects had no regular primary care doctor. A regular primary care doctor was defined as the doctor whom the persons who usually consulted when he/she was ill. A family doctor was defined as the doctor whom the person would consult for all their health problems.

The difference in hospital-based health service utilization was investigated in two ways. The first one was by the prevalence (likelihood) of use of the health services during the last episode of illness, while the second one was the monthly utilization rate of hospital-based (emergency service and in-patient) services. It was estimated that $10 \%$ of the population belonged to RFD group who would have 0.48 consultations per month [22,28,29]. A minimum sample size of 3000 subjects was estimated in order to be able to detect a $15 \%$ difference in number of consultations over a period of 4 weeks across three comparison groups with $80 \%$ power and $5 \%$ level of significance by Poisson regression.

\section{Outcome measures}

Primary outcome measures were the prevalence (likelihood) of the health services utilization (i.e. utilization of hospital emergency service or admission or consultation with primary care doctors per subject) during the last episode of illness. Secondary outcome measures were the monthly rates of doctor consultation (number of visits to the doctors over the past 4 weeks per subject).

\section{Data analysis}

Multiple logistic regression analyses were used to determine the effects of having a RFD on likelihood of hospital admission, emergency visits or specialist consultations in the last episode of illness by adjusting for possible confounding factors of socio-demographics, health status, lifestyles, chronic morbidity and seasonality. Model goodness-of-fit of logistic regressions was assessed using the Hosmer-Lemeshow test. Utilization rates were compared across three groups by Poisson regression analyses when adjusted for confounding variables. Negative binomial regression models were used instead of Poisson regression models in cases when the ratio of residual deviance to degrees of freedom was far greater than one, indicating the overdispersed count outcomes.

All estimates were accompanied with a $95 \%$ confidence interval and a p-value $<0.05$ was considered as statistically significant. The SPSS 20.0 Window (SPSS 
Inc., Chicago, USA) was used to perform the statistical analysis.

This study was approved by the Institutional Review Board of the University of Hong Kong/ Hospital Authority Hong Kong West Cluster (HKU/HA HKW IRB \# UW 07-021). The trial registration number for this study is ClinicalTrials.gov ID: NCT01422031.

\section{Results}

Amongst the 3148 subjects, 1896 (60.2\%) reported that they had a regular primary care doctor. Of which, $60.7 \%$ (1150, 36.5\% of total population) claimed their regular doctors as family doctors, while $39.3 \%$ (746, $23.7 \%$ of total population) claimed their regular doctors not their family doctors. On the whole, 1256 (39.9\%) said they had a family doctor and majority $(91.6 \%)$ of them $(1150$, $36.5 \%$ of total population) said their family doctors were their regular primary care doctors. The remaining 106 subjects $(8.4 \%)$ who said they had a family doctor but their family doctors were not their regular primary care doctors were excluded from analysis for our study purpose because these subjects did not fit into any of our pre-set three subject groups. Table 1 shows the sociodemographic and morbidity characteristics of the subjects. The RFD group had more subjects who were female (61.9\%), had household monthly income > HKD \$20,000
(58.0\%), and were younger (mean age 38.5 years), when compared with the ORD and NRD groups.

Multiple logistic regressions found that younger age, currently married, white-collar work, higher household monthly incomes, having a chronic disease, need longterm medications and regular exercise were independent factors associated with having a regular primary care doctor (Table 2).

\section{Prevalence (Likelihood) of health services utilization}

The prevalence (likelihood) of health services utilization during the last episode of illness of the population is shown in Table 3. Amongst the 3148 subjects, $71.7 \%$ consulted a doctor, $7.3 \%$ visited emergency service and $3.1 \%$ were hospitalized. The RFD group were the least likely to visit emergency service or admitted to the hospital, while there was no significant difference between ORD and NRD groups. The NRD group was significantly less likely to consult but more likely than the others to visit emergency service (9.6\%).

\section{Health service utilization rate}

The monthly health service utilization rates based on the number of consultations during the past four weeks reported by study subjects are shown in Table 4. One third of the population had used one or more medical

Table 1 Characteristics of subjects by primary care doctor choice groups

\begin{tabular}{|c|c|c|c|c|}
\hline & $\begin{array}{l}\text { Total* } \\
(\mathrm{n}=3148)\end{array}$ & $\begin{array}{l}\text { RFD } \\
(n=1150)\end{array}$ & $\begin{array}{l}\text { ORD } \\
(n=746)\end{array}$ & $\begin{array}{l}\text { NRD } \\
(n=1157)\end{array}$ \\
\hline$\overline{\text { Age }(\text { mean } \pm \text { s.d. }) \dagger}$ & $40.2 \pm 18.1$ & $38.5 \pm 17.6$ & $40.1 \pm 18.0$ & $41.3 \pm 18.5$ \\
\hline$<25$ yrs (\%) & 23.0 & 21.9 & 23.8 & 24.1 \\
\hline $25-64$ yrs (\%) & 68.0 & 72.8 & 67.4 & 63.9 \\
\hline$\geq 65$ yrs (\%) & 9.0 & 5.3 & 8.7 & 12.0 \\
\hline Male (\%) & 40.9 & 38.1 & 39.4 & 44.9 \\
\hline Married (\%) & 54.9 & 57.1 & 53.6 & 53.2 \\
\hline Education $\leq$ primary school (\%) & 17.4 & 13.4 & 17.1 & 20.7 \\
\hline Household income $<$ HKD\$20,000 (\%) †キ & 53.1 & 42.0 & 52.0 & 64.1 \\
\hline \multicolumn{5}{|l|}{ Occupation (\%) } \\
\hline Managerial/ Admin/ Professionals/ Employer & 12.5 & 15.9 & 12.3 & 9.7 \\
\hline White collar workers & 16.5 & 19.5 & 17.5 & 13.0 \\
\hline Blue collar/ Service sales worker & 20.4 & 17.4 & 21.7 & 23.0 \\
\hline Chronic disease (\%) & 34.7 & 34.8 & 38.2 & 30.8 \\
\hline Long term medications (\%) & 22.8 & 23.7 & 25.1 & 19.5 \\
\hline \multicolumn{5}{|l|}{ General Health condition (\%) } \\
\hline Excellent/Very good/Good & 48.7 & 53.2 & 41.3 & 50.0 \\
\hline Fair & 44.9 & 42.3 & 49.2 & 44.3 \\
\hline Poor & 6.4 & 4.3 & 9.5 & 5.8 \\
\hline
\end{tabular}

Notes: RFD = Regular family doctor group; ORD = Other regular doctor group; NRD = No regular doctor group.

*The sum of three groups did not add up to total, as 95 respondents were not sure if they had regular/ family doctors. †Significant difference between RFD and NRD by one way ANOVA test or chi-square test, as appropriate.

¥Median monthly domestic household income of Hong Kong population $=$ HKD\$17,250 (Census and Statistics Department, 2006). 
Table 2 Factors associated with a regular primary care doctor by logistic regression

\begin{tabular}{|c|c|c|c|}
\hline Independent variables & Odds ratio & $95 \% \mathrm{Cl}$ & P-value \\
\hline$\overline{\text { Age }}$ & 0.987 & $(0.978-0.997)$ & 0.010 \\
\hline Sex (male) & 1.204 & $(0.974-1.488)$ & 0.087 \\
\hline Marital status (single/ divorced/ widower) & & & 0.044 \\
\hline - Married & 1.333 & $(1.047-1.697)$ & 0.019 \\
\hline - Refuse to answer & 0.741 & $(0.239-2.300)$ & 0.604 \\
\hline Educational level (nil/ primary) & & & 0.092 \\
\hline - Secondary & 1.319 & $(1.008-1.725)$ & 0.043 \\
\hline - Tertiary & 1.082 & $(0.774-1.512)$ & 0.645 \\
\hline - Refuse to answer & 0.765 & $(0.245-2.391)$ & 0.645 \\
\hline Household monthly income $(<\$ 5,000)$ & & & $<0.001$ \\
\hline$-\$ 5,000-\$ 9,999$ & 0.868 & $(0.551-1.369)$ & 0.543 \\
\hline$-\$ 10,000-\$ 19,999$ & 1.487 & $(0.970-2.279)$ & 0.069 \\
\hline$-\$ 20,000-\$ 29,999$ & 2.243 & $(1.422-3.537)$ & $<0.001$ \\
\hline$-\$ 30,000-\$ 39,999$ & 2.594 & $(1.583-4.252)$ & $<0.001$ \\
\hline$-\geq \$ 40,000$ & 3.384 & $(2.108-5.432)$ & $<0.001$ \\
\hline - Refuse to answer & 2.056 & $(1.311-3.224)$ & 0.002 \\
\hline Occupation (blue-collar worker/ service and sales worker) & & & 0.010 \\
\hline - Managerial/ administrative/professional/ employer & 1.362 & $(0.953-1.946)$ & 0.090 \\
\hline - White-collar worker & 1.525 & $(1.116-2.084)$ & 0.008 \\
\hline - Student & 1.057 & $(0.713-1.568)$ & 0.781 \\
\hline - Home-maker & 1.142 & $(0.825-1.581)$ & 0.423 \\
\hline - Retired/ unemployed & 0.746 & $(0.518-1.074)$ & 0.115 \\
\hline - Others & 0.961 & $(0.446-2.074)$ & 0.920 \\
\hline Chronic disease (yes) & 0.738 & $(0.573-0.950)$ & 0.018 \\
\hline Long term medication (yes) & 0.559 & $(0.415-0.753)$ & $<0.001$ \\
\hline General Health Condition (poor) & & & 0.467 \\
\hline - Excellent & 1.333 & $(0.727-2.444)$ & 0.353 \\
\hline - Very good & 1.572 & $(0.966-2.557)$ & 0.069 \\
\hline- Good & 1.381 & $(0.865-2.206)$ & 0.177 \\
\hline - Fair & 1.358 & $(0.874-2.110)$ & 0.173 \\
\hline Smoking (yes) & 1.206 & $(0.938-1.551)$ & 0.144 \\
\hline Drinking (yes) & 1.139 & $(0.932-1.393)$ & 0.203 \\
\hline Regular exercise (no/ don't know) & 1.372 & $(1.131-1.665)$ & 0.001 \\
\hline
\end{tabular}

Notes: Variable in brackets is the reference category for independent variables. Logistic regression (enter): Odds ratio $<1$ (less likely than the reference category), Odds ratio $>1$ (more likely than the reference category).

services including $24.7 \%$ who had consulted communitybased Western medicine doctors, 9.6\% consulted Chinese medicine practitioners, $3.7 \%$ had visited emergency service, and $1.2 \%$ was admitted to the hospital. The mean primary care consultation rate was 0.71 (95\%C.I. 0.66, 0.75) per person with $8 \%$ of which provided by the emergency service. The RFD group had the lowest monthly illness rate $(0.51)$, and they had the lowest emergency service utilization rate $(0.05)$. The consultation rate of the NRD group was lower (0.49) than those of the others (0.85) but they were more likely than the RFD group to have used emergency service. The highest utilization rate of emergency service was found in the ORD group.

\section{Effects of primary care doctor choice on health service utilization}

The differences in outcomes between different primary care doctor choice groups were compared pair-wise by multiple regressions on the data, adjusting for all possible confounders.

Table 5 shows the results of multiple logistic regressions of doctor choice groups on the pattern of service 
Table 3 Prevalence (Likelihood) of the use of Health services during the last episode of illness by primary care doctor choice groups

\begin{tabular}{|c|c|c|c|c|}
\hline Last episode of illness & $\begin{array}{l}\text { Total } \\
(n=3148)\end{array}$ & $\begin{array}{l}\text { RFD } \\
(n=1150)\end{array}$ & $\begin{array}{l}\text { ORD } \\
(n=746)\end{array}$ & $\begin{array}{l}\text { NRD } \\
(n=1157)\end{array}$ \\
\hline Had consulted any doctors $(\%)^{*} \dagger \neq$ & 71.7 & 80.2 & 74.7 & 60.8 \\
\hline - Had used any Western doctor (\%)*†‡ & 65.4 & 77.6 & 68.1 & 51.3 \\
\hline - Consulted family doctor $(\%)^{*} † \ddagger$ & 30.2 & 67.0 & 10.6 & 7.0 \\
\hline - Consulted regular PC doctor who is not a family doctor (\%)†‡ & 27.5 & 16.8 & 54.7 & 19.4 \\
\hline - Consulted other doctors $(\%)^{*} \dagger$ & 19.7 & 14.3 & 13.1 & 29.0 \\
\hline - Consulted Chinese medicine practitioner (\%) & 12.1 & 13.1 & 13.1 & 10.6 \\
\hline - Visited emergency service $(\%)^{*} \ddagger$ & 7.3 & 4.3 & 7.8 & 9.6 \\
\hline - Admitted to the hospital $(\%)^{*} \neq$ & 3.1 & 1.7 & 3.6 & 4.0 \\
\hline
\end{tabular}

Notes: RFD = Regular family doctor group; ORD = Other regular doctor group; $\mathrm{NRD}=$ No regular doctor group.

*Significant difference $(p<0.05)$ between RFD and NRD by univariable logistic regression.

†Significant difference $(p<0.05)$ between ORD and NRD by univariable logistic regression.

¥Significant difference $(p<0.05)$ between RFD and ORD by univariable logistic regression.

utilization during the last episode of illness. RFD group was more likely than the NRD and ORD groups to have consulted. RFD had around 38-54\% lower odds of using emergency service or hospital admissions than the ORD and NRD groups, but there was no difference between the ORD and NRD groups.

Negative Binomial regressions were used for overdispersed count outcomes of monthly consultation rate whereas monthly emergency service visit rate and monthly hospital admission rate were tested by Poisson regressions
(Table 6). Seasonality (summer vs. winter) was also adjusted for and treated as a covariate. The RFD and ORD groups had $54.0 \%$ to $64.7 \%$ more consultations than the NRD group, with no difference between the RFD and ORD groups. After controlling for confounding variables, the difference in emergency service or hospital admission rates between doctor choice groups was not statistically significant. Seasonality had the strongest effect on service utilization rates, with higher rates found in the winter.

Table 4 Monthly consultation and service utilization rates by primary care doctor choice groups

\begin{tabular}{|c|c|c|c|c|}
\hline & $\begin{array}{l}\text { Total } \\
(\mathrm{n}=3148)\end{array}$ & $\begin{array}{l}\text { RFD } \\
(n=1150)\end{array}$ & $\begin{array}{l}\text { ORD } \\
(n=746)\end{array}$ & $\begin{array}{l}\text { NRD } \\
(n=1157)\end{array}$ \\
\hline & \multicolumn{4}{|c|}{ mean \pm s.d, $(\%$ of subjects $)$} \\
\hline \multirow[t]{2}{*}{ Monthly consultation rate*† } & $0.71 \pm 1.53$ & $0.85 \pm 1.73$ & $0.85 \pm 1.60$ & $0.49 \pm 1.26$ \\
\hline & $(33.6 \%)$ & (39.1\%) & $(38.3 \%)$ & $(25.2 \%)$ \\
\hline \multirow[t]{2}{*}{ - Western medicine doctors*† } & $0.43 \pm 1.00$ & $0.61 \pm 1.22$ & $0.50 \pm 1.06$ & $0.20 \pm 0.62$ \\
\hline & $(24.7 \%)$ & $(33.6 \%)$ & $(28.5 \%)$ & $(13.5 \%)$ \\
\hline \multirow[t]{2}{*}{ - Western medicine family doctors* $† \ddagger$} & $0.21 \pm 0.75$ & $0.50 \pm 1.10$ & $0.06 \pm 0.41$ & $0.03 \pm 0.26$ \\
\hline & $(12.8 \%)$ & (30.1\%) & $(3.5 \%)$ & $(2.0 \%)$ \\
\hline \multirow[t]{2}{*}{ - Western medicine regular but not family doctors* $+\neq$} & $0.22 \pm 0.65$ & $0.11 \pm 0.40$ & $0.44 \pm 0.98$ & $0.17 \pm 0.56$ \\
\hline & $(14.4 \%)$ & $(8.9 \%)$ & $(26.1 \%)$ & $(11.9 \%)$ \\
\hline \multirow[t]{2}{*}{ - Chinese medicine practitioner*十‡ } & $0.24 \pm 1.03$ & $0.24 \pm 1.04$ & $0.32 \pm 1.12$ & $0.19 \pm 0.97$ \\
\hline & $(9.6 \%)$ & $(10.0 \%)$ & $(12.5 \%)$ & $(7.5 \%)$ \\
\hline \multirow[t]{2}{*}{ - Hospital emergency servicełł } & $0.06 \pm 0.45$ & $0.05 \pm 0.56$ & $0.08 \pm 0.47$ & $0.05 \pm 0.29$ \\
\hline & $(3.7 \%)$ & $(2.3 \%)$ & $(5.2 \%)$ & $(3.8 \%)$ \\
\hline \multirow[t]{2}{*}{ Monthly Hospital admission rate } & $0.01 \pm 0.14$ & $0.01 \pm 0.14$ & $0.02 \pm 0.15$ & $0.01 \pm 0.13$ \\
\hline & $(1.2 \%)$ & $(1.0 \%)$ & $(1.3 \%)$ & $(1.1 \%)$ \\
\hline
\end{tabular}

Notes: RFD = Regular family doctor group; ORD = Other regular doctor group; $\mathrm{NRD}=$ No regular doctor group.

*Significant difference between RFD and NRD by univariable Poisson regression.

†Significant difference between ORD and NRD by univariable Poisson regression.

‡Significant difference between RFD and ORD by univariable Poisson regression. 
Table 5 Effects of primary care doctor choice on use of health services during the last episode of illness

\begin{tabular}{|c|c|c|c|c|c|}
\hline \multirow[t]{2}{*}{$\begin{array}{l}\text { Logistic regression } \\
\text { results }\end{array}$} & \multirow[b]{2}{*}{ Overall significance } & RFD vs. NRD† & RFD vs. ORD + & ORD vs. NRD $†$ & \multirow[t]{2}{*}{$\begin{array}{l}\text { Other significant independent } \\
\text { variables }(p<0.05) \neq\end{array}$} \\
\hline & & \multicolumn{3}{|c|}{ Odds ratio (95\% C.I.) } & \\
\hline \multirow[t]{2}{*}{$\begin{array}{l}\text { Any primary care doctor } \\
\text { consultation }\end{array}$} & \multirow[t]{2}{*}{0.012} & *2.486 & $* 1.342$ & $* 1.853$ & \multirow[t]{2}{*}{$\begin{array}{l}\text { Drinking, regular exercise, occupation } \\
\text { marital status }\end{array}$} \\
\hline & & $(2.053,3.010)$ & $(1.074,1.676)$ & $(1.509,2.275)$ & \\
\hline \multirow[t]{2}{*}{ Emergency service visit } & \multirow[t]{2}{*}{$<0.001$} & ${ }^{*} 0.479$ & ${ }^{*} 0.624$ & 0.768 & \multirow{2}{*}{$\begin{array}{l}\text { Age, general health, long-term } \\
\text { medication, household monthly } \\
\text { income, district }\end{array}$} \\
\hline & & $(0.330,0.695)$ & $(0.411,0.949)$ & $(0.536,1.098)$ & \\
\hline \multirow[t]{2}{*}{ Hospital admission } & \multirow[t]{2}{*}{0.032} & ${ }^{*} 0.458$ & ${ }^{*} 0.514$ & 0.891 & \multirow[t]{2}{*}{ Age, long-term medication } \\
\hline & & $(0.267,0.788)$ & $(0.284,0.932)$ & $(0.540,1.470)$ & \\
\hline
\end{tabular}

Notes: RFD = Regular family doctor group; ORD = Other regular doctor group; NRD = No regular doctor group.

* Statistically significant $(\mathrm{p}<0.05)$ difference.

tas reference category for doctor choice groups in logistic regression, Odds ratio $<1$ (less likely than the reference category), Odds ratio $>1$ (more likely than the reference category).

¥Adjustment of confounding factors including socio-demographics, health status, chronic morbidity and lifestyle (Additional file 1).

\section{Discussion}

This study found that the public prone to differentiate family doctors from other primary care doctors, based on the function of the doctor. Around two-third (67.0\%) of people having regular family doctor consulted their own family doctors for their last episode of illness. We defined a regular primary care doctor as a doctor whom one would first consult when one needs to, and a family doctor as a doctor whom one would consult for all types of health problems. About two-third (60.2\%) of the subjects said that they had a regular primary care doctor, which was similar to the $56 \%$ found in an earlier study [28]. More than one-third (36.5\%) said that they had a family doctor as their regular primary care doctor; which was higher than the $10 \%$ reported by the earlier study that used a narrower definition based on qualification for family doctor [28]. People who were younger, employed as white-collar workers and having higher incomes were more likely to have a family doctor, probably because they were more health conscious as indicated by a higher likelihood of regular exercise. A higher awareness and a better access to family-doctor led primary care may also be the reasons for the difference.

\section{Prevalence (Likelihood) of health service utilization and utilization rates}

An important function of primary care is to gate-keep hospital emergency and admission services. Consistent with local and oversea findings, only a very small minority (1.2\% in 4 weeks) of people needed in-hospital treatment and $90 \%$ of the medical service was provided by primary care excluding the emergency service (Table 4). People with RFD were about $50 \%$ less likely than others to have visited the emergency service or being hospitalized for

Table 6 Effects of primary care doctor choice on monthly consultation and health service utilization rates

\begin{tabular}{|c|c|c|c|c|c|}
\hline & & RFD vs NRD + & RFD vs ORDt & ORD vs NRD† & $\begin{array}{l}\text { Other significant independent variables } \\
(p<0.05) \neq\end{array}$ \\
\hline & $\begin{array}{l}\text { Overall } \\
\text { significance }\end{array}$ & \multicolumn{4}{|c|}{ Coefficient (95\% C.I.) } \\
\hline \multicolumn{6}{|l|}{ Negative Binomial Regression Results } \\
\hline \multirow[t]{2}{*}{ Monthly consultation rate } & \multirow[t]{2}{*}{$<0.001$} & ${ }^{*} 0.473$ & 0.046 & ${ }^{*} 0.427$ & \multirow{2}{*}{$\begin{array}{l}\text { Seasonality, sex, general health, chronic } \\
\text { disease, drinking, occupation, educational } \\
\text { level, district }\end{array}$} \\
\hline & & $(0.332,0.614)$ & $(-0.098,0.191)$ & $(0.273,0.581)$ & \\
\hline \multicolumn{6}{|l|}{ Poisson Regression Results } \\
\hline \multirow{2}{*}{$\begin{array}{l}\text { Monthly emergency service } \\
\text { visit rate }\end{array}$} & \multirow[t]{2}{*}{0.158} & 0.253 & -0.099 & 0.352 & \multirow{2}{*}{$\begin{array}{l}\text { Seasonality, sex, age, general health, } \\
\text { long-term medication, occupation, } \\
\text { household monthly income, educational } \\
\text { level, district }\end{array}$} \\
\hline & & $(-0.140,0.647)$ & $(-0.490,0.292)$ & $(-0.038,0.742)$ & \\
\hline \multirow[t]{2}{*}{ Monthly hospital admission rate } & \multirow[t]{2}{*}{0.360} & -0.047 & -0.253 & 0.206 & \multirow[t]{2}{*}{ Seasonality } \\
\hline & & $(-0.764,0.670)$ & $(-1.013,0.507)$ & $(-0.553,0.965)$ & \\
\hline
\end{tabular}

Notes: RFD = Regular family doctor group; ORD = Other regular doctor group; $\mathrm{NRD}=$ No regular doctor group. *Statistically significant $(p<0.05)$ difference.

tas reference category in Poisson/Negative Binomial regression, +ve: positive relationship, -ve: negative relationship.

¥Seasonality with phase I data coded as Summer and phase 2 data coded as Winter was entered as a covariate, and adjustment for confounding factors including socio-demographics, health status, chronic morbidity and lifestyle (Additional file 1). 
their last episode of illnesses, after controlling for confounding factors including health status (Table 5). It should be noted that having other regular primary care doctors did not significantly reduce the use of emergency service or hospital services, when compared with people without any regular primary care doctor. Our findings are coherent with that patient-centred care, which was a key element of family medicine, was related to a significantly decreased annual number of visits for specialty care and less frequent hospitalizations [30].

About one third of the population had used primary medical services (33.6\%). The primary care service utilization rate $(33.5 \%)$ was similar to the $37.2 \%$ of primary care consultations found in the 2002 Thematic Household Survey, although the prevalence of emergency service visit and Chinese medicine practitioner consultations reported by our subjects were higher [22]. About $67 \%$ of RFD subjects consulted their family doctors during the last episode of illness and $54.7 \%$ of the ORD group consulted their regular doctors, validating their claims of having a regular primary care doctor and showing that there was a better continuity of care with a family doctor.

Availability and accessibility of primary health care influenced the rate of hospitalization in which an accessible and readily available primary health care system lowered the hospitalization and admission rate [31,32]. Continuity of care, which was a key feature of the practice of family medicine, was shown to be associated with a decreased future likelihood of hospitalization [33], and it was also demonstrated in our study that having a regular family doctor reduced their likelihood of using emergency service or secondary hospital services. In other words, people with regular family doctors had easier access to primary care and thus led to a lower demand for hospital-based (both emergency and in-hospital) health services. On the other hand, our study showed that people with RFD consulted doctors more frequently in the past 4 weeks amongst the three groups of people, and their hospital admission rate was the lowest amongst the three groups. A study found out that the visit rates of general practitioners correlated negatively with the rates of hospitalizations [34] and an engagement with a good and effective primary care program reduced the use of emergency services $[35,36]$ which to some extent compatible with the lowest odd ratio for the RFD group for the emergency service usage and hospital admission.

The population-adjusted mean monthly consultation rate was 0.7 (95\% CI $0.65,0.75)$, which is equivalent to 8.4 (95\% CI. 7.8, 9) consultations per year [25]. The rate was consistent with the 9 consultations per year found in the population survey in 1998 [23], and the monthly Western medicine consultation rate was similar to the 0.48 found in another local population survey in 1998 [29], supporting the consistency of the results. There was an impression that the population in Hong Kong used more health services than overseas populations $[22,23]$. The annual consultation rate of the Hong Kong population was actually similar to the 6.8 and 8.7 found in the US young adult men and women, respectively [30]. Although the figure was much higher than that found in Canada (median 3.3) [31], it was still much lower than the 13.4 visits in Taiwan [32]. The projected annual western medicine consultation rate was around 5 that is in par with that found in Australia and the United Kingdom [33,34]. It is interesting to note that the Chinese medicine practitioner consultations by the $9.5 \%$ subjects made up one third (33.5\%) of the total volume of medical service used. The 'excess' in consultation rates found in the Hong Kong population was the result from the concomitant use of Western and Chinese medicine consultations, which are often not counted in studies in Western countries. This implied that users of Chinese medicine were more likely to have repeated consultations. There is no standard on the optimal consultation rate for a population, which is dependent on the complex interaction between patients' perceived needs, availability and accessibility of doctors and payment methods $[30,31,35]$.

It seemed contradicting to find that the RFD group had the highest consultation rate when they reported the lowest illness rate. The strongest determinants of health service utilization are perceived health need and accessibility of services [37]. Having a family doctor or other regular primary care doctor probably does not alter a person's perception of illness but increases accessibility to care. People with regular primary care doctors may also be more inclined to consult because they had positive experience from previous consultations. The possibility of lower ability of coping with illness and higher doctor dependence among people with RFD deserve further research. The findings alerted to the problem of low accessibility to community-based primary care doctor service in the NRD group who may then rely more on emergency service as a source for primary care.

\section{Limitations}

A loose definition of the family doctor was used in this study and the classification into RFD, ORD, and NRD groups was based on subjective self-reporting and its accuracy cannot be verified. This might have affected the results on the between-group differences, but the bias would be more likely to under-estimate rather than overestimate the difference. It was interesting to note that a small percentage of ORD and NRD groups (people who stated that they did not have a family doctor as their regular primary care doctor) reported visiting their family doctors in their last episode of illness. This reflected that some people may have their own interpretation of what a 
family doctor should be. Indeed the definition of a family doctor from the patients' perspectives deserves further exploratory studies.

The study sample was not fully representative of the general population with an over representation of people who were female, younger, and better educated. We tried to adjust for these confounding variables in the regression analyses so that the results can be more generalizable. The results of our analyses were mainly based on the data from the cross-sectional study, which is subject to recall bias and the uncertainty of a causal or effect relationship. Also, the emergency service visit and hospital admission rate were based on 4-week period instead of longer period (e.g. one-year), which may contribute to the low monthly rate obtained. This might have underestimated the rates of use of these health services.

\section{Conclusions}

Primary care is the most effective among people with a regular family doctor in terms of gate-keeping of emergency and hospital in-patient services in the Hong Kong health care system with a variety of primary care doctors. The concepts of primary care and family doctor are being recognized by the public in Hong Kong. Majority $(60.2 \%)$ of the population reported having a regular primary care doctor and one third (36.5\%) had a regular family doctor. The emergency service was used by a significant $7.3 \%$ of the population for primary care during the last episode of illness, and at even a higher prevalence $(9.6 \%)$ among people without a regular primary care doctor. The findings supported the adoption of a family-doctor led primary care service in Hong Kong and possibly other Asian countries. The challenge is how to help every citizen find a regular family doctor and to enable more primary care doctors to become family doctors. The public should have access to more information on primary care practitioners so that they can choose one who can serve as their family doctors. Better manpower planning with more postgraduate family medicine training opportunities is urgently needed to increase the supply of family doctors.

\section{Additional file}

Additional file 1: 1: Notes on Independent Variables in the

Regression Analyses. 2: Full details of regression coefficients of all

independent variables in the logistic, Poisson and Negative binomial

regression analyses.

\section{Abbreviations}

RFD: Regular family doctor group; ORD: Other regular doctor group; NRD: No regular doctor group; US: Unites States; UK: United Kingdom.

\section{Competing interests}

The authors declare that they have no competing interests.

\section{Authors' contributions}

CLKL provided direct input into the design and execution of the study. CW and DYTF undertook statistical analysis and generated the results. CSCF, CW, AL and CLKL drafted the manuscript and contributed to its editing. All authors read and approved the final manuscript.

\section{Acknowledgements}

This study was supported by the Studies in Health Services Grant (No. SHS-P-10) from the Food and Health Bureau of the Hong Kong Special Administrative Region. The authors would like to thank Richard Au Yeung, Mandy Tai and the Social Sciences Research Centre of the University of Hong Kong for their help in data collection, and Ms Charlotte Yu for technical editing.

\section{Support}

This study was supported by the Studies in Health Services Grant (No. SHS-P-10) from the Food and Health Bureau of the Hong Kong Special Administrative Region.

\section{Author details}

'Department of Family Medicine and Primary Care, the University of Hong Kong, 3/F., 161 Main Street, Ap Lei Chau Clinic, Ap Lei Chau, Hong Kong. ${ }^{2}$ School of Nursing, the University of Hong Kong, 4/F, William M.W. Mong Block, 21 Sassoon Road, Pokfulam, Hong Kong. ${ }^{3}$ Centre for Health Education and Health Promotion, The Jockey Club School of Public Health and Primary Care, the Chinese University of Hong Kong, 4/F, Lek Yuen Health Centre, 9 Lek Yuen Street, Shatin, Hong Kong.

Received: 30 April 2014 Accepted: 14 January 2015

Published online: 28 January 2015

\section{References}

1. WHO. The Alma-Ata conference on primary health care. WHO Chron. 1978;32:409-30.

2. WHO. Health for all policy in the 21st century. Geneva: WHO; 1998

3. Howie JG, Heaney DJ, Maxwell M, Walker JJ, Freeman GK, Rai H. Quality at general practice consultations: cross sectional survey. BMJ. 1999;319(7212):738-43

4. Macinko J, Starfield B, Shi L. The contribution of primary care systems to health outcomes within Organization for Economic Cooperation and Development (OECD) countries, 1970-1998. Health Serv Res. 2003:38(3):831-65.

5. Starfield B. Is primary care essential? Lancet. 1994;344(8930):1129-33.

6. Starfield B. Improving equity in health: a research agenda. Int J Health Serv. 2001;31(3):545-66.

7. WHO. The world health report 2000- health systems: improving performance. Geneva: WHO; 2000

8. Starfield B, Shi L, Macinko J. Contribution of primary care to health systems and health. Milbank Q. 2005;83(3):457-502

9. Starfield B. Global health, equity, and primary care. J Am Board Fam Med. 2007;20(6):511-3.

10. Ferrer RL, Hambridge SJ, Maly RC. The essential role of generalists in health care systems. Ann Intern Med. 2005;142:691-9.

11. Food and Health Bureau HKSARG. Your health your life healthcare reform consultation document. 2008.

12. Franks P, Fiscella K. Primary care physicians and specialists as personal physicians. Health care expenditures and mortality experience. J Fam Pract. 1998;47(2):105-9.

13. Gulliford MC. Availability of primary care doctors and population health in England: is there an association? J Public Health Med. 2002;24(4):252-4

14. Shi L, Macinko J, Starfield B, Wulu J, Regan J, Politzer R. The relationship between primary care, income inequality, and mortality in US States, 1980-1995. J Am Board Fam Pract. 2003;16(5):412-22.

15. Campbell RJ, Ramirez AM, Perez K, Roetzheim RG. Cervical cancer rates and the supply of primary care physicians in Florida. Fam Med. 2003;35(1):60-4.

16. Weinberger M, Oddone EZ, Henderson WG. Does increased access to primary care reduce hospital readmissions? Veterans affairs cooperative study group on primary care and hospital readmission. N Engl J Med. 1996;334(22):1441-7.

17. Weingarten SR, Lloyd L, Chiou C-F, Braunstein GD. Do subspecialists working outside of their specialty provide less efficient and lower-quality care to 
hospitalized patients than do primary care physicians? Arch Intern Med. 2002;162(5):527-32.

18. Ferrante JM, Gonzalez EC, Pal N, Roetzheim RG. Effects of physician supply on early detection of breast cancer. Am Board Fam Pract. 2000;13(6):408-14.

19. Health and Medical Development Advisory Committee, Health, Welfare and Food Bureau. Building a healthy tomorrow - discussion paper on the future service delivery model for our health care system. In: Hong Kong SAR government. 2005. p. 1-80

20. Bodenheimer T. Primary care - will it survive? N Engl J Med. 2006;355(9):861-4.

21. Lee A, Lau FL, Hazlett CB, Kam CW, Wong P, Wong TW, et al. Factors associated with non-urgent utilization of Accident and Emergency services: a case-control study in Hong Kong. Soc Sci Med. 2000;51 (7):1075-85.

22. Leung GM, Wong IOL, Chan W-S, Choi S, Lo S-V, Health Care Financing Study, Group. The ecology of health care in Hong Kong. Soc Sci Med. 2005;61(3):577-90

23. The Harvard Team. Improving Hong Kong's health care system: why and for whom? Hong Kong SAR: Government Printing Department; 1999.

24. Leung GM, Castan-Cameo S, McGhee SM, Wong IOL, Johnston JM. Waiting time, doctor shopping, and nonattendance at specialist outpatient clinics: case-control study of 6495 individuals in Hong Kong. Med Care. 2003:41(11):1293-300.

25. Lam CLK, Leung GM, Mercer SW, Fong DYT, Lee A, Lam TP, et al. Utilisation patterns of primary health care services in Hong Kong: does having a family doctor make any difference? Hong Kong Med J. 2011;17 Suppl 3:28-32.

26. Lam CLK, Wong CKH, Lam ETP, Lo YYC, Huang WW. Population norm of Chinese (HK) SF-12 Health Survey_Version 2 of Chinese adults in Hong Kong. HK Practitioner. 2010;32(2):77-86.

27. Lam CLK, Yu EYT, Lo YYC, Wong CKH, Fong DYT, Lee A, et al. Having a family doctor is associated with some better patient reported outcomes of primary care consultations. Front Med. 2014;1:29.

28. HKCFP Research Committee. What sort of primary healthcare service does the public want? Hong Kong Pract. 2008;30:24-8.

29. Lam CLK, Fong DYT, Lauder IJ, Lam T-PD. The effect of health-related quality of life (HRQOL) on health service utilisation of a Chinese population. Soc Sci Med. 2002;55(9):1635-46.

30. Bertakis KD, Azari R. Patient-centered care is associated with decreased health care utilization. J Am Board Fam Med. 2011;24(3):229-39.

31. Dourado I, Oliveira VB, Aquino R, Bonolo P, Lima-Costa MF, Medina MG, et al. Trends in primary health care-sensitive conditions in Brazil: the role of the Family Health Program (Project ICSAP-Brazil). Med Care. 2011:49(6):577-84.

32. Rosano A, Loha CA, Falvo R, van der Zee J, Ricciardi W, Guasticchi G, et al. The relationship between avoidable hospitalization and accessibility to primary care: a systematic review. Eur J Public Health. 2013;23(3):356-60.

33. Gill JM, Mainous III AG. The role of provider continuity in preventing hospitalizations. Arch Fam Med. 1998;7(4):352.

34. Lindström K, Engström S, Bengtsson C, Borgquist L. Determinants of hospitalisation rates: does primary health care play a role? Scand J Prim Health Care. 2003;21(1):15-20

35. Davidson RA, Giancola A, Gast A, Ho J, Waddell R. Evaluation of access, a primary care program for indigent patients: inpatient and emergency room utilization. J Community Health. 2003;28(1):59-64.

36. Van Uden CJ, Winkens RA, Wesseling G, Fiolet HF, Van Schayck OC, Crebolder HF. The impact of a primary care physician cooperative on the caseload of an emergency department: The Maastricht integrated out-of-hours service. J Gen Intern Med. 2005;20(7):612-7.

37. Andersen R, Newman J. Societal and individual determinants of medical care utilization in the United States. Milbank Mem Fund Q. 1973;50:95-124.

\section{Submit your next manuscript to BioMed Central and take full advantage of:}

- Convenient online submission

- Thorough peer review

- No space constraints or color figure charges

- Immediate publication on acceptance

- Inclusion in PubMed, CAS, Scopus and Google Scholar

- Research which is freely available for redistribution

Submit your manuscript at www.biomedcentral.com/submit 